\title{
Urethral Stricture Reconstruction by Buccal Mucosal Graft Technique
}

\author{
Sandeep K Mehla
}

\begin{abstract}
Introduction: A prospective study of 39 cases with stricture urethra who underwent buccal mucosal graft urethroplasty from January 2018 to June 2019 in Department of Urology in Mahatma Gandhi Medical College and Hospital, Jaipur, Rajasthan, India.

Aim and objective: To establish the outcome of urethral stricture reconstruction by a buccal mucosal graft technique.

Materials and methods: The prospective study will be carried out in the Department of Urology, Mahatma Gandhi Medical College and Hospital, Jaipur, for the period of one and half year from January 2018 to June 2019. Inclusion criteria were that all male patients with diagnosis of urethral stricture disease will be included in the study. Exclusion criteria were old fragile medical unfit patients on supra pubic catheter, patient with bleeding dyscrasia, and all females.

Results: In our study, we found that balanitis xerotica obliterans (BXO) is the most common cause of stricture urethra. It is the most common from 31 to 40 years. After the procedure, no donor site complications were seen. Medium and long strictures got excellent outcome. Out of 39 grafts, no graft loss is seen till date in follow-up of 3 and 6 months.

Conclusion: In our study, we found that dorsal onlay is the preferred form of graft placement. Buccal mucosal graft is the ideal substitute for urethra, especially in medium and long segment urethral stricture. Buccal mucosal graft has good graft properties for graft survival. The donor site had no significant complications. Dorsal onlay graft is the preferred type as it has good support better outcome. Nil failure in respect to graft function urine flow patients satisfaction till date. Longer follow-up is need (keeping attrition over a period of time for substitution urethroplasty in mind before coming to definite conclusion).

Keywords

Journal of Mahatma Gandhi University of Medical Sciences \& Technology (2019): 10.5005/jp-journals-10057-0091
\end{abstract}

\section{INTRODUCTION}

Urethral stricture is the narrowing of the caliber of the urethra caused by the presence of a scar consequent on infection or injury. It is one of the most common complications of urethral injuries. Male urethral stricture disease has a substantial impact on quality of life resulting in infection, bladder calculi, fistulas, sepsis, and ultimately renal failure. The incidence of urethral stricture has been estimated at 229-627 cases per 100,000 individuals, with the incidence sharply increasing in people aged $\geq 55$ years.

Strictures can be divided into two main types, anterior and posterior, which differ not only in their location but also in their underlying pathogenesis. Urethral stricture disease is a challenging condition to treat, and several approaches including direct visual internal urethrotomy (DVIU) and anastomotic or augmentation urethroplasties based on the use of flaps and graft have been reported (Figs 1 and 2).

\section{Aim and Objective}

To establish the outcome of urethral stricture reconstruction by a buccal mucosal graft technique.

\section{Materials and Methods}

The prospective study will be carried out in the Department of Urology, Mahatma Gandhi Medical College and Hospital, Jaipur, for the period of one and half year from January 2018 to June 2019.

\section{Inclusion Criteria}

All male patients with diagnosis of urethral stricture disease will be included in the study.
Department of General Surgery, Mahatma Gandhi Medical College, Mahatma Gandhi University of Medical Sciences and Technology, Jaipur, Rajasthan, India

Corresponding Author: Sandeep K Mehla, Department of General Surgery, Mahatma Gandhi Medical College, Mahatma Gandhi University of Medical Sciences and Technology, Jaipur, Rajasthan, India, Phone: +91 96028861532, e-mail: Sandeepmehla1969@rediffmail.com How to cite this article: Mehla SK. Urethral Stricture Reconstruction by Buccal Mucosal Graft Technique. J Mahatma Gandhi Univ Med Sci Tech 2019;4(1):27-28.

Source of support: Nil

Conflict of interest: None

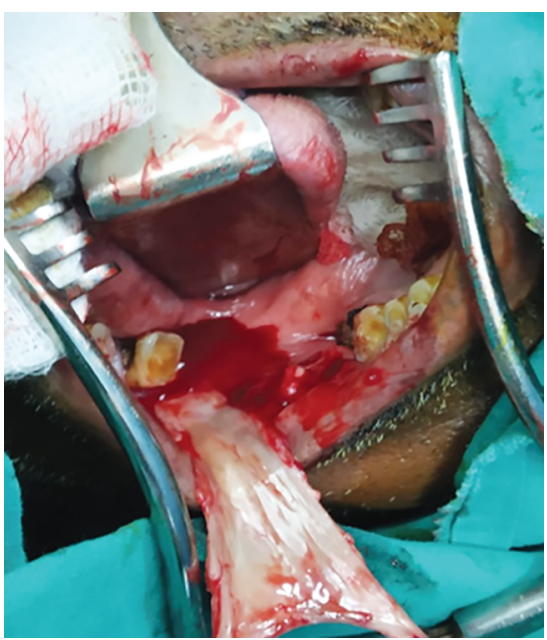

Fig. 1: Graft harvesting from right buccal mucosa

(0) The Author(s). 2019 Open Access This article is distributed under the terms of the Creative Commons Attribution 4.0International License (https://creativecommons. org/licenses/by-nc/4.0/), which permits unrestricted use, distribution, and non-commercial reproduction in any medium, provided you give appropriate credit to the original author(s) and the source, provide a link to the Creative Commons license, and indicate if changes were made. The Creative Commons Public Domain Dedication waiver (http://creativecommons.org/publicdomain/zero/1.0/) applies to the data made available in this article, unless otherwise stated. 


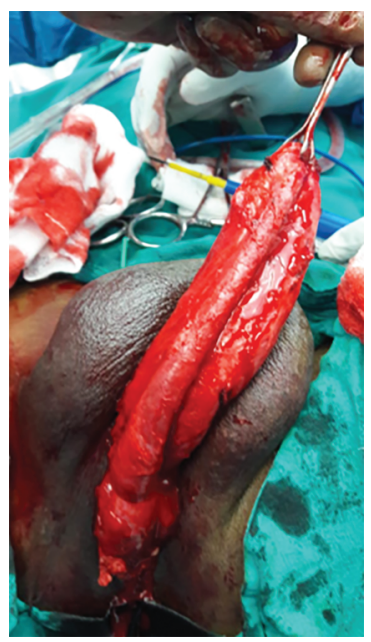

Fig. 2: Invagination of urethra into perineum

Table 1: Age group

\begin{tabular}{lcr}
\hline S. no. & Age group (years) & \\
\hline 1 & $<20$ & 0 \\
2 & $21-30$ & 9 \\
3 & $31-40$ & 12 \\
4 & $41-50$ & 9 \\
5 & $51-60$ & 9 \\
6 & $>60$ & 0 \\
\hline
\end{tabular}

Table 2: Etiology

\begin{tabular}{lll}
\hline S. no. & Etiology & No. of patients \\
\hline 1 & BXO & 21 \\
2 & Post-inflammatory & 15 \\
3 & Postsurgery (iatrogenic) & 3 \\
\hline
\end{tabular}

\section{Exclusion Criteria}

Old fragile medical unfit patients on supra pubic catheter, patient with bleeding dyscrasia, and all females.

\section{Method}

\section{Buccal Mucosal Graft Urethroplasty}

The patient is intubated through the nose, allowing the mouth to be completely free. With the help of mouth retractor, buccal mucosal graft was harvested. The urethroplasty is performed in the high lithotomy position. We used glide wire and 5-F urinary catheter and placed them in bladder. Midline perineal incision is given between root of scrotum to $1 \mathrm{~cm}$ proximal to anal verge and layer by layer opened up till bulbocavernosus muscle. It was subsequently incised in midline and laid open. In case of pan urethral strictures (15 patients), penis was invaginated, and the urethra was separated from corpus cavernosum up to the meatus. Penile invagination was done in perineum. Urethra was dissected away from corporal body on the left side and lifted to around 2/3 of its circumference and laid open posterolaterally in its complete length of stricture and $1-2 \mathrm{~cm}$ beyond normal urethral caliber at both the ends which were confirmed by passage of meatal dilators. Now, the harvested graft was laid dorsally over the bed formed by corporal bodies and intercrural space and fixed on the bed by using 3.0 vicryl (Polygalactin) in 2-3 parallel lines. Urethrotomy was closed over 16-F silicon catheter anastomosed with the lateral edge of buccal mucosal graft by interrupted or continuous sutures.
Table 3: Length of strictures

\begin{tabular}{lll}
\hline S. no. & Length of stricture $(\mathrm{cm})$ & No. of patients \\
\hline 1 & $2-5$ & 18 \\
2 & $5-10$ & 6 \\
3 & $\geq 11$ & 15 \\
\hline
\end{tabular}

Table 4: Complications

\begin{tabular}{lll}
\hline S. no. & Total no. & Significant complications \\
\hline 1 & 39 & 0 \\
\hline
\end{tabular}

Bulbocavernosus muscle and fascial covering was done. Wound closed in layers and no drain placed. In postoperative period, mouth packs were removed after 24 hours (Tables 1 to 4 ).

\section{Results}

In our study, we found that balanitis xerotica obliterans (BXO) is the most common cause of stricture urethra. It is the most common from 31 to 40 years. After the procedure, no donor site complications were seen. Medium and long strictures got excellent outcome. Out of 39 grafts, no graft loss is seen till date in follow-up of 3 and 6 months.

\section{Conclusion}

In our study, we found that dorsal onlay is the preferred form of graft placement. Buccal mucosal graft is the ideal substitute for urethra, especially in medium and long segment urethral stricture. Buccal mucosal graft has good graft properties for graft survival. The donor site had no significant complications. Dorsal onlay graft is the preferred type as it has good support better outcome. Nil failure in respect to graft function urine flow patients satisfaction till date. Longer follow-up is need (keeping attrition over a period of time for substitution urethroplasty in mind before coming to definite conclusion).

\section{References}

1. Meredith Fairfax Campbell, Patrick C. Walsh, Alan Burton Retik, Campbell's urology Walsh, Retick, Vaughan, 8th edn; 2002.

2. Humby G. A one-stage operation for hypospadias repair. Br J Surg 1941;29(113):84-92. DOI: 10.1002/bjs.18002911312.

3. Bürger RA, Müller SC, el-Damanhoury $\mathrm{H}$, et al. The buccal mucosal graft for urethral reconstruction: a preliminary report. J Urol 1992;147(3):662-664. DOI: 10.1016/s0022-5347(17)37340-8.

4. Duckett JW, Coplen D, Ewalt D, et al. Buccal mucosal urethral replacement. J Urol 1995;153(5):1660-1663. DOI: 10.1016/S00225347(01)67497-4.

5. El-Kasaby AW, Fathalla M, Noweir AM, et al. The use of buccal mucosa patch graft in the management of anterior urethral strictures. J Urol 1993;149(2):2768. DOI: 10.1016/S0022-5347(17)36054-8.

6. Barbagli G, Selli C, di Cello V, et al. A one stage dorsal free graft urethroplasty for bulbar urethral strictures. Br J Urol 1996;78(6): 929-932. DOI: 10.1046/j.1464-410x.1996.23121.x.

7. Kulkarni S, Barbagli G, Sansalone S, et al. One-sided anterior urethroplasty: a new dorsal only graft technique. BJU Int 2009;104(8):1150. DOI: 10.1111/j.1464-410X.2009.08590.x.

8. Mundy' AR, Andritch. Urethral strictures and their surgical management. BJU Int 2011;107(1):6-26. DOI: 10.1111/j.1464410X.2010.09800.x.

9. Barbagli G, Palminteri E, Lazzeri M, et al., Anterior urethral strictures. BJU Int 2003;92(5):497-505. DOI: 10.1046/j.1464-410x.2003.04379.x.

10. Dubey D, Sehgal A, Srivastava A, et al., Buccal mucosal urethroplasty for BalanitisXerotica Obliterans related urethral strictures. The outcome of I \& II stage techniques. J Urol 2005;173(2):463-466. DOI: 10.1097/01.ju.0000149740.02408.19. 